JRNAL ПMПAH

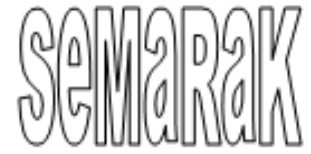

P-ISSN 2615-6849, E-ISSN 2622-3686

Jurnal Semarak,Vol.4,No.1,Februari 2021, Hal (130-139)

@Prodi Manajemen Fakultas Ekonomi Universitas Pamulang

\title{
PENGARUH BUDAYA KERJA TERHADAP PRESTASI KERJA KARYAWANPT. BANK MANDIRI MITRA USAHA GUNUNG SINDUR BOGOR
}

\author{
Caryoto \\ Dosen universitas pamulang, \\ email: dosen02561@unpam.ac.id
}

\begin{abstract}
Abstrak
Bertujuan untuk mengetahui budaya kerja karyawan, untuk mengetahui prestasi kerja karyawan dan untuk mengetahui pengaruh budaya kerja terhadap prestasi kerja karyawan PT. Bank Mandiri Mitra Usaha Gunung Sindur Bogor.

Metode penelitian bersifat asosiatif kuantitatif yaitu data penelitian bersifat berhubungan antara dua variabel, dengan penyajian datanya berupa angka-angka dan analisis menggunakan statistik. Populasi dalam penelitian adalah 53 orang, sedangkan sampel meggunakan sampel jenuh sebanyak 53 responden. Metode pengumpulan data penelitian dengan menggunakan observasi, wawancara, kuesioner (angket) dan studi dokumentasi. Sedangkan metode analisis data menggunaka uji validitas, uji realibilitas, persamaan regresi linier sederhana, koefisien korelasi sederhana, koefisien determinasi danuji signifikansi.

Hasil penelitian menunjukan bahwa budaya kerja secara umum masih kategori baik. Hal ini dapat dilihat dari jawaban responden yang sangat setuju sebesar 25,09\%, setuju sebesar 52,08 \%, ragu-ragu sebesar $21,13 \%$, tidak setuju 1,51\%, dan jawaban sangat tidak setuju $0,19 \%$. Prestasi karyawan secara umum masih kategori baik. Hal ini dapat dilihat dari jawaban responden yang menjawab sangat setuju sebesar 33,58 \%, setuju 52,45\%, ragu-ragu sebesar $13,02 \%$, tidak setuju $0,94 \%$ dan jawaban yang sangat tidak setuju sebesar $0 \%$. Nilai persamaan regresi liner sederhana dalam penelitian yaitu $\overline{\mathrm{Y}}=18,09+0,594 \mathrm{X}$ jika budaya kerja meningkat maka akan meningkatkan prestasi kerja karyawan, begitu pula sebaliknya. Nilai koefisien korelasi sebesar $r=0,773$ yang berarti korelasi antara budaya kerja terhadap prestasi kerja karyawan berada dikategori kuat. Nilai Determinasi yang diperoleh sebesar 59,7 \% menunjukan bahwa prestasi karyawan dipengaruhi oleh budaya kerja sebesar 59,7 \% sisanya sebesar 40,3\% dipengaruhi oleh faktor lain, $t_{\text {hitung }}>\mathrm{t}_{\text {tabel }}$ yaitu 0,642 >0,271 maka Ho ditolak dan Ha diterima artinya terdapat pengaruh yang signifikan antara budaya kerja terhadap prestasi kerja karyawan PT Bank Mandiri Mitra Usaha Gunung Sindur Bogor.
\end{abstract}

\section{Kata Kunci : Budaya Kerja Dan Prestasi Kerja Karyawan}

\begin{abstract}
Absract
Aiming to find out the work culture of employees, to find out the work performance of employees and to determine the effect of work culture on employee performance PT. Bank Mandiri Gunung Sindur Bogor Business Partner.
\end{abstract}


The research method is quantitative associative namely the research data is related between two variables, with the presentation of the data in the form of numbers and analysis using statistics. The population in the study was 53 people, while the sample used a saturated sample of 53 respondents. Research data collection methods using observation, interviews, questionnaires (questionnaire) and study documentation. While the data analysis method uses the validity test, reliability test, simple linear regression equation, simple correlation coefficient, determination coefficient and significance test.

The results showed that the work culture in general is still a good category. This can be seen from the answers of respondents who strongly agree at $25.09 \%$, agree at $52.08 \%$, doubt at $21.13 \%$, disagree $1.51 \%$, and answers strongly disagree $0.19 \%$. Employee performance in general is still in the good category. This can be seen from the answers of respondents who answered strongly agreed at $33.58 \%$, agreed $52.45 \%$, doubtful at $13.02 \%$, disagreed $0.94 \%$ and answers that strongly disagreed at $0 \%$. The value of the simple linear regression equation in the study is $\bar{Y}=18.09+0.594 \mathrm{X}$ if work culture increases it will increase employee performance, and vice versa. Correlation coefficient value of $r=0.773$ which means the correlation between work culture and employee performance is in the strong category. Determination value obtained by $59.7 \%$ shows that employee achievement is influenced by work culture by $59.7 \%$ while the remaining $40.3 \%$ is influenced by other factors, tcount> ttable is $0.642>0.271$ then Ho is rejected and $\mathrm{Ha}$ is accepted meaning there is an influence significant between the work culture of PT Bank Mandiri Mitra Usaha Gunung Sindur Bogor's work performance.

\section{Keywords: Work Culture and Employee Work Performance}

\section{PENDAHULUAN Pendahuluan}

Perusahaan adalah suatu lembaga yang diorganisir dan dijalankan untuk menyediakan barang dan jasa agar dapat melayani permintaan konsumen akan kebutuhan mereka. Dalam melaksanakan proses produksinya, suatu perusahaan membutuhkan faktor-faktor produksi yang dapat menunjang tercapainya tujuan perusahaan. Faktor-faktor tersebut adalah bahan baku, modal, dan manusia. Budaya kerja sudah lama dikenal oleh manusia, namun belum disadari bahwa suatu keberhasilan kerja itu berakar pada nilai nilai yang dimiliki dan perilaku yang menjadi kebiasaan (Supriyadi dan Guno, $2006: 1$ ).

\section{Tabel 1.1}

\section{Absensi Karyawan PT. Bank Mandiri Mitra Usaha Gunung Sindur Bogor}

\begin{tabular}{|l|c|c|c|c|c|c|c|c|c|c|c|c|}
\hline \multicolumn{1}{|c|}{ Keterangan } & Jan & Feb & Mar & Apr & Mei & Jun & Jul & Ags & Sep & Okt & Nov & Des \\
\hline Sakit & 6 & 4 & 3 & 6 & 5 & 3 & 3 & 6 & 7 & 5 & 6 & 3 \\
\hline Izin/ Cuti & 6 & 2 & 2 & 0 & 1 & 2 & 7 & 4 & 5 & 1 & 4 & 1 \\
\hline Absen & 3 & 2 & 1 & 3 & 3 & 2 & 1 & 0 & 1 & 2 & 0 & 1 \\
\hline Total Tidak Hadir & 15 & 8 & 6 & 9 & 9 & 7 & 11 & 10 & 13 & 8 & 10 & 5 \\
\hline Total Hadir & 38 & 45 & 47 & 44 & 44 & 46 & 42 & 43 & 40 & 45 & 43 & 48 \\
\hline \multicolumn{1}{|c}{ Jumlah } & 53 & 53 & 53 & 53 & 53 & 53 & 53 & 53 & 53 & 53 & 53 & 53 \\
\hline
\end{tabular}

Sumber: PT. Bank Mandiri Mitra Usaha Gunung Sindur Bogor, diolah

Dalam tabel tersebut hampir setiap bulan ada saja karyawan yang tidak hadir dalam bekerja. Hal ini menunjukan rendahnya tingkat kesadaran karyawan untuk menerapkan budaya kerja secara disiplin dan konsisten.

Dari permasalahan diatas, penulis akan menganalisanya dengan memberi judul Pengaruh Budaya Kerja terhadap Prestasi Kerja PT. Bank Mandiri Mitra Usaha Gunung Sindur Bogor.

\section{B. Perumusan Masalah}

Berdasarkan latar belakang yang telah diuraikan diatas maka dapat dirumuskan permasalahan yang terjadi yaitu:

1. Bagaimana penerapan budaya kerja yang dilakukan di PT. Bank Mandiri Mitra Usaha Gunung Sindur Bogor ?

2. Bagaimana tingkat prestasi kerja karyawan di PT. Bank Mandiri Mitra Usaha Gunung Sindur Bogor ? 
3. Seberapa besar pengaruh budaya kerja terhadap prestasi kerja karyawan PT. Bank Mandiri Mitra Usaha Gunung Sindur Bogor ?

\section{Tujuan Penelitian}

Adapun tujuan dari penelitian yang dilakukann ini antara lain :

a. Untuk mengetahui pelaksanaan budaya kerja yang dilakukan PT. Bank Mandiri Mitra Usaha Gunung Sindur Bogor .

b. Untuk mengetahui tingkat prestasi kerja karyawan di PT. Bank Mandiri Mitra Usaha Gunung Sindur Bogor.

c. Untuk mengetahui besarnya pengaruh budaya kerja terhadap prestasi kerja karyawan PT. Bank Mandiri Mitra Usaha Gunung Sindur Bogor.

\section{Kajian Literatur}

\section{Budaya Kerja}

Budaya kerja menurut Supriyadi (2003:69) adalah suatu falsafah yang didasari oleh pandangan hidup, sebagai nilai nilai yang menjadi sifat dan kekuatan pendorong membudaya dalam kehidupan suatu kelompok masyarakat atau organisasi kemudian tercermin dari sikap menjadi perilaku, kepercayaan, citacita, pendapat, dan tindakan yang terwujud sebagai kerja atau bekerja.

\section{Prestasi Kerja}

Adapun menurut Malayu S.P. Hasibuan (2008:94) prestasi kerja adalah suatu hasil kerja yang dicapai seseorang dalam melaksanakan tugas-tugas yang dibebankan kepadanya yang didasarkan atas kecakapan dan kesungguhan serta waktu.

\section{Kerangka Berfikir}

Dari uraian kerangka pemikiran diatas, maka dapat digambarkan paradigma penelitian sebagai berikut :

\section{Metodologi Penelitian}

Objek Penelitian ini Metode analisis yang digunakan dalam penelitian ini adalah uji validitas, uji reliabilitas, uji koefisien determinasi, uji korelasi product moment, $\mathrm{Uji}$ t. Populasi dalam penelitian ini adalah seluruh karyawan PT Bank Mandiri Mitra Usaha Gunung Sindur berjumlah 53 orang. Dalam penentuan jumlah sampel tersebut, peneliti menggunakan sampling jenuh yaitu seluruh populasi dijadikan sampel sebanyak 53 orang.

\section{Hasil dan Pembahasan}

Uji Validitas Variabel Budaya Kerja

Tabel 1.2

Rangkuman Analisa Validitas

Variabel Budaya Kerja (X)

\begin{tabular}{|c|c|c|c|}
\hline $\begin{array}{c}\mathbf{N} \\
\mathbf{0}\end{array}$ & $\begin{array}{c}\mathbf{r}- \\
\mathbf{h i t u n}\end{array}$ & $\begin{array}{c}\mathbf{r}- \\
\text { tabel }\end{array}$ & $\begin{array}{c}\text { Keteranga } \\
\mathbf{n}\end{array}$ \\
\hline $\mathbf{1}$ & 0.372 & $\begin{array}{c}0.27 \\
1\end{array}$ & VALID \\
\hline $\mathbf{2}$ & 0.518 & $\begin{array}{c}0.27 \\
1\end{array}$ & VALID \\
\hline $\mathbf{3}$ & 0.289 & $\begin{array}{c}0.27 \\
1\end{array}$ & VALID \\
\hline $\mathbf{4}$ & 0.294 & $\begin{array}{c}0.27 \\
1\end{array}$ & VALID \\
\hline $\mathbf{5}$ & 0.314 & $\begin{array}{c}0.27 \\
1\end{array}$ & VALID \\
\hline $\mathbf{6}$ & 0.497 & $\begin{array}{c}0.27 \\
1\end{array}$ & VALID \\
\hline $\mathbf{7}$ & 0.528 & $\begin{array}{c}0.27 \\
1\end{array}$ & VALID \\
\hline $\mathbf{8}$ & 0.521 & $\begin{array}{c}0.27 \\
1\end{array}$ & VALID \\
\hline $\mathbf{9}$ & 0.411 & $\begin{array}{c}0.27 \\
1\end{array}$ & VALID \\
\hline
\end{tabular}




\begin{tabular}{|l|l|c|l|} 
& & 0.27 & \\
$\mathbf{1 0}$ & 0.405 & 1 & VALID \\
\hline
\end{tabular}

Berdasarkan hasil uji validitas tersebut dapat diketahui bahwa keseluruhan nilai $r$ hitung $>r$ tabel 0,271 dengan demikian maka dapat disimpulkan bahwa semua item pernyataan dalam indikator variabel budaya kerja adalah valid.

\section{Uji Validitas Variabel Prestasi Kerja}

Tabel 1.3

\section{Rangkuman Analisa Validitas Variabel Prestasi Kerja (Y)}

\begin{tabular}{|c|c|c|c|}
\hline No & r-hitung & r-tabel & $\begin{array}{c}\text { Keteranga } \\
\mathbf{n}\end{array}$ \\
\hline $\mathbf{1}$ & 0.407 & 0.271 & VALID \\
\hline $\mathbf{2}$ & 0.512 & 0.271 & VALID \\
\hline $\mathbf{3}$ & 0.271 & 0.271 & VALID \\
\hline $\mathbf{4}$ & 0.295 & 0.271 & VALID \\
\hline $\mathbf{5}$ & 0.293 & 0.271 & VALID \\
\hline $\mathbf{6}$ & 0.291 & 0.271 & VALID \\
\hline $\mathbf{7}$ & 0.396 & 0.271 & VALID \\
\hline $\mathbf{8}$ & 0.396 & 0.271 & VALID \\
\hline $\mathbf{9}$ & 0.394 & 0.271 & VALID \\
\hline $\mathbf{1 0}$ & 0.276 & 0.271 & VALID \\
\hline
\end{tabular}

Berdasarkan hasil uji validitas tersebut dapat diketahui bahwa keseluruhan nilai $r$ hitung $>r$ tabel 0,271 dengan demikian maka dapat disimpulkan bahwa semua item pernyataan dalam indikator variabel prestasi krjaadalah valid.

\section{Uji Reliabilitas}

Tabel 1.4

\section{Hasil Uji Reliabilitas}

\begin{tabular}{|c|c|c|c|}
\hline $\begin{array}{c}\text { Varia } \\
\text { bel }\end{array}$ & $\begin{array}{c}\text { Nilai } \\
\text { Cronb }\end{array}$ & $\begin{array}{c}\text { Krite } \\
\text { ria }\end{array}$ & $\begin{array}{c}\text { Keput } \\
\text { usan }\end{array}$ \\
\hline
\end{tabular}

\begin{tabular}{|l|l|l|l|}
\hline & $\begin{array}{c}\text { ach } \\
\text { Alpha }\end{array}$ & & \\
\hline $\begin{array}{l}\text { Buda } \\
\text { ya } \\
\begin{array}{l}\text { Kerja } \\
\text { (X) }\end{array}\end{array}$ & 0,311 & 0,271 & Tinggi \\
\hline $\begin{array}{l}\text { Presta } \\
\text { si } \\
\text { Kerja } \\
\text { (Y) }\end{array}$ & 0,642 & 0,271 & Tinggi \\
\hline
\end{tabular}

Berdasarkan tabel diatas dapat diketahui bahwa masing-masing variabel antara variabel kualitas pelayanan dan kepuasan nasabah, memiliki nilai Cronbach Alpha $\geq 0,60$. Dengan demikian maka hasil uji reliabilitas terhadap keseluruhan variabel adalah tinggi. sehingga semua butir pertanyaan dapat dipercaya dan dapat digunakan untuk penelitian selanjutnya.

\section{Analisis Deskriptif}

\section{Deskripsi Variabel Budaya Kerja}

Tabel 1.5

Tabel Data Distribusi Jawaban Variabel X (Budaya Kerja)

Sumber: Kuesioner diolah peneliti (2017)

Jumlah hasil pernyataan $=\mathrm{SS}+\mathrm{S}+\mathrm{RR}+\mathrm{TS}$ $+\mathrm{STS}=133+276+122+8+1=530$ dan selanjutnya untuk mencari persentase jawaban adalah setiap jumlah pernyataan di kalikan $100 \%$ berikut adalah cara penghitungannya:

Jawaban SS

$$
: \frac{133}{530} \times 100=
$$

$25.09 \%$

Jawaban S

$52.08 \%$

Jawaban RR $: \frac{122}{530} \times 100=21.13 \%$

Jawaban TS : $\frac{8}{530} \times 100=$ $1.51 \%$

Jawaban STS $: \frac{1}{600} \times 100=0.19 \%$ 
Pelaksanaan budaya kerja pada PT. Bank Mandiri Mitra Usaha Gunung Sindur Bogor mendapat respon yang baik bahwa penerapan budaya kerja sudah baik dapat dilihat dari jawaban kuesioner dengan total yang menjawab setuju dan sangat setuju sejumlah $52.08 \%+25.09 \%=77,17 \%$

\section{Deskripsi Variabel Prestasi Kerja}

Tabel 1.6

Tabel Data Distribusi Jawaban Variabel Y (Prestasi Kerja)

Perhitungan prestasi kerja karyawan seluruh jawaban yang diperoleh dari pernyataan variabel prestasi kerja diambil dari jumlah hasil dari 10 pernyataan $\mathrm{SS}+\mathrm{S}+\mathrm{R}+\mathrm{TS}+\mathrm{STS}$ yaitu $178+278+69+5+0=530$. Selanjutnya untuk mencari persentase jawaban adalah tiap total jawaban dibagi jumlah pernyataan lalu dikali $100 \%$ contoh sebagai berikut:

$$
\begin{gathered}
S S=\frac{178}{530} \times 100 \% \\
=33,58 \% \\
S=\frac{278}{530} \times 100 \%=52,45 \% \\
R=\frac{69}{530} \times 100 \% \\
=13,02 \% \\
T S=\frac{5}{530} \times 100 \% \\
\text { STS }=\frac{0}{530} \times 100 \%=0 \%
\end{gathered}
$$

Berdasarkan hasil kuesioner penerapan budaya kerja yang optimal akan berperngaruh baik pada prestasi kerja karyawan pada PT. Bank Mandiri Mitra Usaha Gunung Sindur mendapat respon yang baik. bahwa pretasi kerja dapat dilihat dari jawaban kuesioner dengan total yang menjawab setuju dan sangat setuju sejumlah $52.45 \%+33.58 \%=$ $86.03 \%$

\section{Analisis Verifikatif}

\section{Uji Regresi Linier Sederhana}

Regresi linier sederhana merupakan suatu metode yang digunakan untuk mengukur besarnya pengaruh variabel bebas terhadap variabel tergantung dan memprediksi variabel tergantung dengan variabel bebas.

Metode ini juga bisa digunakan sebagai ramalan, sehingga dapat diperkirakan antara baik atau buruknya suatu variabel $X$ terhadap naik turunnya suatu tingkat variabel $\mathrm{Y}$ begitupun sebaliknya. Berikut rumus regresi linier sederhana.

$$
\mathrm{Y}=\mathrm{a}+\mathrm{bx}
$$

a. Mencari nilai $b$

$$
\begin{aligned}
& \mathrm{b}=\frac{n\left(\sum x y\right)-\left(\sum x\right)\left(\sum y\right)}{n \sum x^{2}-\left(\sum x\right)^{2}} \\
& \mathrm{~b}=\frac{53(89328)-(2121)(2219)}{53(85765)-(2121)^{2}} \\
& \mathrm{~b}=\frac{4734384-4706499}{4545455-4498641} \\
& \mathrm{~b}=\frac{27885}{46904}=0,594 \\
& \mathrm{~b} . \quad \text { Mencari nilai a } \\
& \frac{\sum y-\mathrm{b} \sum x}{n} \\
& \mathrm{a}=\frac{2219-0,594(2121)}{53} \\
& \mathrm{a}=\frac{2219-1259,88}{53} \\
& \mathrm{a}=\frac{959,12}{53} \\
& =18,09
\end{aligned}
$$

Maka persamaan regresi sederhana yaitu:

$$
\begin{array}{ll}
\mathrm{Y} & =18,09+0,549 \mathrm{X} \\
\mathrm{Y} & =18,639
\end{array}
$$

Dengan demikian dapat diperoleh angka persamaan berdasarkan persamaan garis regresi yang diperoleh $\mathrm{Y}=18,09+0,594 \mathrm{X}$ artinya bahwa perubahan $\mathrm{Y}$ searah dengan perubahan 
$X$. Jadi nilai $Y$ akan meningkat jika $X$ meningkat,sebaliknya nilai $\mathrm{Y}$ akan menurun jika nilai $X$ menurun. Jadi dapat disimpulkan bahwa budaya kerja berpengaruh positif terhadap prestasi karyawan artinya jika budaya kerja meningkat maka akan meningkat kan prestasi karyawan, begitu pula sebaliknya.

\section{Uji Koefisien Korelasi}

Berikut tabel hasil kuesioner responden varian butir-butir variabel budaya kerja dan prestasi kerja berdasarkan uji validitas.

$$
\begin{aligned}
& \text { Diketahui : } \\
& \sum \mathrm{x}=2121 \\
& \sum \mathrm{x}^{2}=85765 \\
& \sum \mathrm{y}=2219 \\
& \sum \mathrm{y}^{2}=93429 \\
& \sum \mathrm{xy}=89328
\end{aligned}
$$

Dari data diatas, penulis gunakan untuuk mengetahui pengaruh antara variabel $\mathrm{x}$ (budaya kerja) dengan variabel y (prestasi kerja) dengan menggunakan rumus korelasi sebagai berikut :

$$
\begin{gathered}
r_{x y}=\frac{\mathrm{n}\left(\sum \mathrm{xy}\right)-\left(\sum \mathrm{x}\right) \cdot\left(\sum \mathrm{y}\right)}{\sqrt{\left\{n \cdot \sum x^{2}-\left(\sum \mathrm{x}\right)^{2}\right\} \cdot\left\{n \cdot \sum y^{2}-\left(\sum \mathrm{y}\right)^{2}\right\}}} \\
=\frac{53(89328)-(2121)(2219)}{\sqrt{53(85765)-(2121)^{2} \cdot 53(93429)-(2219)^{2}}} \\
r_{x y} \frac{4734384-4706499}{\sqrt{(4545545-4498641) \cdot(4951737-4923961)}} \\
r_{x y}=\frac{27885}{\sqrt{46904.27776}} \\
r_{x y}=\frac{27885}{\sqrt{1302805504}} \\
r_{x y}=\frac{27885}{36094,39}
\end{gathered}
$$

$$
r_{x y}=0,773
$$

Dari hasil perhitungan tersebut koefisien korelasi variabel $\mathrm{X}$ dan variabel $\mathrm{Y}$ bertanda positif yaitu dengan besarnya $r=0,773$ yang termasuk kategori kuat $(0,60-0,779)$ kemudian untuk mengetahui seberapa besar pengaruh budaya kerja terhadap prestasi karyawan adalah dengan menggunakan koefisien determinasi.

\section{Uji Koefisien Determinasi}

Koefisien determinasi bertujuan untuk mengetahui seberapa besar kemampuan variabel independen menjelaskan variabel dependen, berikut adalah rumus untuk menentukan koefisien determinasi:

$$
\mathrm{KD}=r^{2} \times 100 \%
$$

Dimana :

$\mathrm{KD}=$ Besar koefisien penentu (determinasi)

$r=$ Koefisien korelasi antara $\mathrm{X}$ dan $\mathrm{Y}$

$$
\begin{aligned}
\mathrm{KD} & =r^{2} \mathrm{X} 100 \% \\
& =(0,773)^{2} \times 100 \% \\
& =0,597 \times 100 \% \\
& =59,7 \%
\end{aligned}
$$

Hal ini membuktikan bahwa besarnya pengaruh budaya kerja terhadap prestasi karyawan sebesar 59,7\% dan sisanya sebesar 40,3\% dipengaruhi beberapa faktor lain.

\section{Uji Hipotesis (uji t)}

Data-data yang dihasilkan dari hasil analisis variabel $(\mathrm{X})$ independent dan variabel (Y) dependent perlu dilakukan uji signifikansi. Untuk mengetahui hubungan keduanya dengan menggunakan uji-t

$$
t=\frac{\mathrm{r} \sqrt{\mathrm{n}-2}}{\sqrt{1-\mathrm{r}^{2}}}
$$


Maka penyelesainnya:

$$
\begin{aligned}
& t=\frac{0,773 \sqrt{53-2}}{\sqrt{1-0,773^{2}}} \\
& t=\frac{0,773 \sqrt{51}}{\sqrt{1-0,5975}} \\
& t=\frac{0,773 \cdot 7,141}{\sqrt{0,4043}} \\
& t=\frac{5,519}{0,636}=8,677
\end{aligned}
$$

Dengan derajat kesamaan $(\mathrm{dk})=\mathrm{n}-2=$ $53-2=51$ dan $\alpha=5 \%\left(\frac{0,05}{2}=0,025\right)$ maka didapat nilai t-tabel dari $5 \%$ $(0,025) .48=2,000 \quad$ (Sugiyono, 2011;332, tabel distribusi t). Dari perhitungan diatas telah diketahui bahwa t-hitung sebesar 8,677 dan $\mathrm{t}$ tabel sebesar 2,000. $\mathrm{T}_{\text {olah }} \mathrm{H}_{\mathrm{o}}$ atau diterima $\mathrm{H}_{\mathrm{a}}$, karena t-hitung > t-tabel $(8,677>2,000)$, berarti bahwa terdapat pengaruh yang signifikan antara budaya kerja terhadap prestasi karyawan.

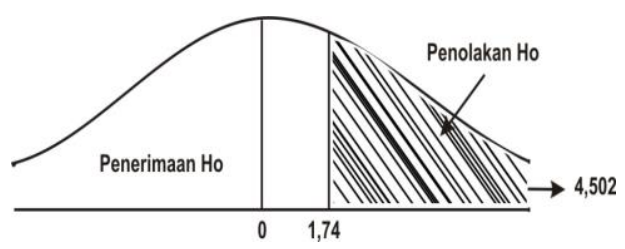

\section{Gambar 1.1}

\section{Kurva Uji Hipotesis (Uji t)}

\section{Kesimpulan}

1. Pelaksanaan

budaya kerja pada PT. Bank Mandiri Mitra Usaha Gunung Sindur Bogor mendapat respon yang baik bahwa penerapan budaya kerja sudah baik dapat dilihat dari jawaban kuesioner dengan total yang menjawab setuju dan sangat setuju sejumlah $52.08 \%+25.09 \%=$ $77,17 \%$

2. Berdasarkan hasil kuesioner penerapan budaya kerja yang optimal akan berperngaruh baik pada prestasi kerja karyawan pada PT. Bank Mandiri Mitra Usaha Gunung Sindur mendapat respon yang baik. bahwa pretasi kerja dapat dilihat dari jawaban kuesioner dengan total yang menjawab setuju dan sangat setuju sejumlah $52.45 \%+33.58 \%=$ $86.03 \%$

3. Dengan demikian dapat diperoleh angka persamaan berdasarkan persamaan garis regresi yang diperoleh $\mathrm{Y}=18,09+$ $0,594 \mathrm{X}$ Dari hasil perhitungan tersebut koefisien korelasi variabel $\mathrm{X}$ dan variabel $\mathrm{Y}$ bertanda positif yaitu dengan besarnya $r=0,773$ yang termasuk kategori kuat $(0,60$ - 0,779) kemudian untuk mengetahui seberapa besar pengaruh budaya kerja terhadap prestasi karyawan adalah dengan

2,0 menggunal $\quad 8,677$ determinas membuktikan bahwa besarnya pengaruh budaya kerja terhadap prestasi karyawan sebesar 59,7 \% dan sisanya sebesar 40,3 $\%$ dipengaruhi beberapa faktor lain. Dengan derajat kesamaan $(\mathrm{dk})=\mathrm{n}-2=53$ - 
$2=51$ dan $\alpha=5 \%\left(\frac{0,05}{2}=\right.$ $0,025)$ maka didapat nilai t-tabel dari $5 \%(0,025) .48$ $=2,000 \quad$ (Sugiyono, 2011;332, tabel distribusi t). Dari perhitungan diatas telah diketahui bahwa thitung sebesar 8,677 dan ttabel sebesar 2,000. $\mathrm{T}_{\text {olah }}$ $\mathrm{H}_{\mathrm{o}}$ atau diterima $\mathrm{H}_{\mathrm{a}}$, karena t-hitung > t-tabel $(8,677>$ 2,000), berarti bahwa terdapat pengaruh yang signifikan antara budaya kerja terhadap prestasi karyawan.

\section{Saran}

1. Menurut hasil dari jawaban responden variabel budaya kerja mendapat respon yang kurang baik pada indikator ketepatan dan rasionalitas, disarankan agar pimpinan menginstruksikan

kepada karyawan untuk menerapkan sikap kehati-hatian dan analisa yang detail pada setiap pengajuan kredit nasabah dan menerapkan target kerja sesuai ketentuan dengan bijak kepada karyawan. 2. Berdasarkan hasil dari jawaban responden variabel prestasi kerja mendapat respon yang kurang baik pada indikator komunikasi, disarankan pada pimpinan PT. Bank Mandiri Mitra Usaha
Gunung Sindur Bogor perlu meningkatkan komunikasi yang baik pada setiap karyawannya agar terjalin kebersamaan lingkungan kerja yang harmonis.

\section{DAFTAR PUSTAKA}

Arifin, Imamul dan Giana Hadi W, 2007."Membuka Cakrawala Ekonomi”. PT. Setia Purna, Jakart.

Assauri, Sofjan. 2004. Manajemen Pemasaran. Jakarta: Rajawali Press.

Pemasaran", 2014. "Manajemen Persada: Jakarta.

Becherel, Lionel Vellas Francois. 2018. "Pemasaran Pariwisata Internasional". Yayasan Obor Indonesia. Jakarta.

Dharmemesta dan Handoko, 2011, Manajemen Pemasara: Analisis Perilaku Konsumen, BPFE, Yogyakarta.

Ghozali, Imam, 2006.“Aplikasi Analisis Multivariate Dengan SPSS". Cetakan keempat. Badan penerbit Universitas Diponegoro, Semarang.

Handoko, 2012, Manajemen Personalia dan Sumber Daya Manusia, Penerbit, BPFE, Yogyakarta.

Hasibuan, Melayu S.P. 2009. Manajemen: Dasar,Pengertian, dan MasalahEdisi Revisi.Jakarta : Bumi Aksara. 
,2014, Manajemen Sumber

Daya Manusia, Edisi Revisi, PT.

Bumi Aksara, Jakarta.

Husein Umar. "Metode Penelitian untuk Skripsi dan Tesis Bisnis". PT Raja Grafindo Persada, Jakarta, 2008.

Istijanto, 2009. "Aplikasi Praktis Riset Pemasaran", Gramedia Pustaka Utama, Jakarta.

Kotler, Philip. 2002. Marketing Management. New Jersey: The Millennium Edition, PrenticeHall International Edition.

2009. "Manajemen Pemasaran", Edisi 13. Erlangga. Jakarta.

2012. "Manajemen

Pemasaran Perspektif Asia”, Buku Dua, Edisi Pertama, Andy, Yogyakarta.

Kotler And Amstrong. 2008 Principles of Marketing. Prentice Hall: Person Education, Inc

\section{9, Prinsip-prinsip}

Pemasaran Edisi. 13 Jilid 1, PT Indeks Jakarta.

Pemasaran", $\quad \begin{aligned} & \text { 2012. “Prinsip-prinsip } \\ & \text { Edisi13. Jilid1. }\end{aligned}$ Erlangga. Jakarta.

Kotler, Philip dan Kevin Lane Keller, 2008. Manajemen Pemasaran, Jilid 1, Penerbit Erlangga. Jakarta.

2009. "Manajemen Pemasaran", Jilid 1, edisi Ketiga Belas, Terjemahan Bob Sabran, MM, Penerbit Erlangga, Jakarta.
- 2009. Marketing

Manajement. 14th ed. New Jersey: Prentice Hall.

\begin{tabular}{l} 
2009. Alih Bahasa : \\
\hline Benyamin Molan Manajement \\
Pemasaran. Edisi Ketigabelas. Jilid \\
1 dan 2. Cetakan Keempat. PT. \\
Indeks. Jakarta.
\end{tabular}

Krisnaldy, K., Pasaribu, V. L. D., \& Batubara, A. S. (2020). Analisis Pengaruh Kedisiplinan Terhadap Performa Pegawai Kelurahan Rempoa, Kota Tangerang Selatan. Jurnal Mandiri: Ilmu Pengetahuan, Seni, Dan Teknologi,4(2), 131-138.

Krisnaldy, K., Pasaribu, V. L. D., \& Senen, S. (2019). Pengaruh Budaya Organisasi, Lingkungan Kerja Dan Iklim Organisasi Terhadap Motivasi Pegawai Serta Dampaknya Terhadap Kepuasan Kerja. Jurnal Semarak, 2(2), 164-183.

Lupiyoadi, 2011, Manajemen Pemasaran, Rajawali Press, Jakarta.

Lupiyoadi, Rahmat, dan A. Hamdani, 2006, Manajemen Pemasaran Jasa, Salemba Empat, Jakarta.

Malhotra, N.K., "Riset Pemasaran", Edisi keempat, Jilid 1, PT Indeks, Jakarta, 2009.

Ma'ruf, Hendri. 2005. Pemasaran Ritel. Jakarta: Gramedia Pustaka Utama.

Mowen and Miror, 2005, Perilaku Konsumen, Erlangga, Jakarta.

Pasaribu, V. L. D., Susanti, F., \& Hartuti, E. T. K. (2019). Memotivasi Siswa dan Siswi SMK Letris Indonesia di Dalam Menentukan Pilihan Untuk Melanjutkan Pendidikan Atau Bekerja Setelah Lulus 
Sekolah. Jurnal Pengabdian Dharma Laksana, 1(2), 161-172.

Pasaribu, V. L. D., \& Krisnaldy, K. (2018). ANALISIS KEPUASAN JAMA'AH PADA KINERJA DEWAN KEMAKMURAN MASJID ALHIDAYAH PERIODE TAHUN 2017. KREATIF: Jurnal Ilmiah Prodi Manajemen Universitas Pamulang, 6(4), 41-51.

Pasaribu, V. L. D., Krisnaldy, K., \& Warasto, H. N. (2020). Pengaruh Gaya Kepemimpinan, Disiplin Kerja Dan Kompensasi Terhadap Kinerja Pegawai (Studi kasus kelurahan Pisangan Ciputat). Jurnal Disrupsi Bisnis: Jurnal Ilmiah Prodi Manajemen, Fakultas Ekonomi, Universitas Pamulang, 3(1).

Pasaribu, V. L. D., \& Krisnaldy, K. (2020). PENGARUH GAYA KEPEMIMPINAN， DISIPLIN KERJA DAN KOMPENSASI TERHADAP HASIL KINERJA KARYAWAN KELURAHAN PISANGAN CIPUTAT. PROCEEDINGS

UNIVERSITAS PAMULANG, 1(1).

Robbins and Coulter, 2013, Manajemen, Penerbit Erlangga, Jakarta.

Raharjani, Jeni. 2005. Analisis Faktor-faktor yang Mempengaruhi Keputusan Pemilihan Pasar Swalayan Sebagai Tempat Berbelanja. Dalam Jurnal Studi Manajemen \& Organisasi, Vol. 2 No. 1 Hal 1-15

Rangkuti, Freddy. 2009. "Strategi Promosi yang Kreatif", Gramedia. Pustaka Utama. Jakarta.

Safroni, Ladzi. 2012. Manajemen dan Reformasi Pelayanan Publik dalam Konteks Birokrasi Indonesia. Surabaya : Aditya Media Publishing.
Schiffman \& Kanuk, 2007, Perilaku Konsumen, dialihbahasakan oleh Zulkifli Kasip.

Sugiyono, 2013 Metode Penelitian Pendidikan Pendekatan Kuantitatif, Kualitatif, dan $R \& D$. Bandung: Alfabeta. 